\title{
Artemisinin resistance in Plasmodium falciparum is associated with an altered temporal pattern of transcription
}

Sachel Mok ${ }^{1 \dagger}$, Mallika Imwong ${ }^{2,3 \dagger}$, Margaret J Mackinnon ${ }^{4}$, Joan Sim', Ramya Ramadoss ${ }^{1}$, Poravuth $\mathrm{Yi}^{9}$, Mayfong Mayxay ${ }^{5,6}$, Kesinee Chotivanich ${ }^{2}$, Kek-Yee Liong ${ }^{1}$, Bruce Russell ${ }^{7}$, Duong Socheat ${ }^{9}$, Paul N Newton ${ }^{5,8}$, Nicholas PJ Day ${ }^{3,8}$, Nicholas J White $^{3,8}$, Peter R Preiser ${ }^{1}$, François Nosten ${ }^{8,10}$, Arjen M Dondorp ${ }^{3,8^{*}}$ and Zbynek Bozdech ${ }^{1 *}$

\begin{abstract}
Background: Artemisinin resistance in Plasmodium falciparum malaria has emerged in Western Cambodia. This is a major threat to global plans to control and eliminate malaria as the artemisinins are a key component of antimalarial treatment throughout the world. To identify key features associated with the delayed parasite clearance phenotype, we employed DNA microarrays to profile the physiological gene expression pattern of the resistant isolates.

Results: In the ring and trophozoite stages, we observed reduced expression of many basic metabolic and cellular pathways which suggests a slower growth and maturation of these parasites during the first half of the asexual intraerythrocytic developmental cycle (IDC). In the schizont stage, there is an increased expression of essentially all functionalities associated with protein metabolism which indicates the prolonged and thus increased capacity of protein synthesis during the second half of the resistant parasite IDC. This modulation of the P. falciparum intraerythrocytic transcriptome may result from differential expression of regulatory proteins such as transcription factors or chromatin remodeling associated proteins. In addition, there is a unique and uniform copy number variation pattern in the Cambodian parasites which may represent an underlying genetic background that contributes to the resistance phenotype.

Conclusions: The decreased metabolic activities in the ring stages are consistent with previous suggestions of higher resilience of the early developmental stages to artemisinin. Moreover, the increased capacity of protein synthesis and protein turnover in the schizont stage may contribute to artemisinin resistance by counteracting the protein damage caused by the oxidative stress and/or protein alkylation effect of this drug. This study reports the first global transcriptional survey of artemisinin resistant parasites and provides insight to the complexities of the molecular basis of pathogens with drug resistance phenotypes in vivo.
\end{abstract}

Keywords: Plasmodium falciparum, in vivo artemisinin-resistance, field isolates, comparative genomics, comparative transcriptomics

\footnotetext{
* Correspondence: arjen@tropmedres.ac; zbozdech@ntu.edu.sg

† Contributed equally

${ }^{1}$ School of Biological Sciences, Nanyang Technological University, Singapore

${ }^{3}$ Mahidol-Oxford Research Unit, Faculty of Tropical Medicine, Mahidol

University, Thailand

Full list of author information is available at the end of the article
} 


\section{Background}

Artemisinin combination therapy (ACT) is recommended by the World Health Organization as the firstline treatment for falciparum malaria in all endemic regions $[1,2]$. The excellent effectiveness and tolerability of ACTs brought new enthusiasm into world-wide efforts to eliminate human malaria which until today accounts for 243 million cases of infection and 863,000 deaths per annum [3]. The core components of ACTs artemisinin and its derivatives, provide an important alternative to quinoline and antifolate-based compounds. Resistance to these older compounds that emerged on the Thai-Cambodian border and subsequently spread across the world has severely compromised their use and contributed to a dramatic rise in malaria morbidity prior to introduction of the ACTs in the late 1990's [4-7]. Learning from past mistakes, much effort is being invested in proper management of ACTs in order to sustain their efficacy and prevent the spread of resistance [1].

In spite of these efforts, there have been sporadic reports of artemisinin resistance in-vivo and in-vitro for many years (from Yunnan Province, Southwest China [8], Vietnam [9] and French Guiana [10]). Although the biological and clinical significance of these reports were uncertain [11], these early warning signs suggested a possibility of emergence of malaria parasites resistant to artemisinin [12-14]. Recently, unequivocal evidence of reduced artemisinin susceptibility from Western Cambodia has been reported [15]. Curiously, this was also the epicenter of chloroquine and sulfadoxine-pyrimethamine resistance. Dondorp et al. (2009) documented markedly prolonged parasite clearance times (median PCT 84 hours (interquartile range 60 to 96 hours) in Pailin, Western Cambodia. This compares with a median PCT of 48 hours (36 to 66 hours) on the Western border of Thailand [15]. Since this study, reports of delayed parasite clearance have emerged in other parts of the region, including the Thai-Myanmar border [13]. Although it has yet to be established whether artemisinin resistance has spread westward, the possibility of the spread of resistant parasites through Asia to Africa would be disastrous.

The mechanism of artemisinin resistance is unknown. The resistant phenotype detected in Western Cambodia does not associate with any polymorphisms in the established drug resistance markers [15]. In vitro susceptibility testing of parasites which are cleared abnormally slowly in vivo, showed essentially no shift in $\mathrm{IC}_{50}(50 \%$ inhibition concentration) values in vitro [15]. This apparent discrepancy between the experimental and the clinical data may be explained by the reduced susceptibility of Plasmodium parasites at only the ring stage (first third) of its 48 hours intraerythrocytic developmental cycle
(IDC) $[15,16]$. Another phenomenon that has been suggested to explain artemisinin resistance is an increased propensity for these parasites to form "dormant" (or quiescent) rings under artemisinin exposure $[17,18]$. However, this process, suggested by in vitro studies, is unlikely to explain the slow first order decline in parasitemia with time that was observed in Western Cambodian patients treated with artemisinin-based drugs [19]. The reduced artemisinin susceptibility phenotype of the resistant malaria parasites exhibits a heritable pattern suggesting that it has a genetic basis [20]. Identifying the genetic determinants will be crucial for understanding the molecular basis of artemisinin resistance and will also provide an important molecular tool for epidemiological surveys.

Here we carry out genome-wide gene expression analyses in order to identify key elements of a transcriptional profile underlining artemisinin resistance. We show that the $P$. falciparum parasites with slow clearance after artemisinin treatment exhibit reduced expression levels of generic metabolic (e.g. glycolysis, nucleotide metabolism) or cellular (e.g. DNA replication) pathways in the ring and trophozoite stages but strong increased expression of essentially all functionalities associated with protein synthesis, folding and trafficking in the schizont stages. This specific "tune-up" of the transcriptional pattern in these resistant $P$. falciparum isolates is associated with altered expression of a number of genes involved in cell cycle regulation, transcription regulation, chromatin remodeling as well as intracellular signaling. Altogether these results provide the first set of testable genetic markers associated with artemisinin resistance.

\section{Results}

\section{Gene expression associated with artemisinin resistance}

The main purpose of these studies was to characterize the transcriptional profile associated with artemisinin resistance in field isolates of $P$. falciparum [15]. For this, we conducted DNA microarray analyses of parasites collected from patients in Pailin, Western Cambodia which had slow parasite clearance (detectable parasitemia 7896 hours following administration of ACTs; isolates CP025, CP037 and CP040; Additional file 1). For comparison we analyzed transcriptomes of additional Southeast Asian isolates collected from Xepon, Savannakhet Province, Laos (isolates BMT061, BMT076, BMT077, XPN003), from Mae Sot, Thailand (isolates NHP2094, NHP4459, NHP4460), and one additional isolate from Pailin (CP022) with normal clearance ( 54 hour). At the time of collection, all isolates exhibited high synchronicity; $100 \%$ parasites were at the ring stage (Additional file 2). Parasites were then cultured for up to 48 hours in vitro and total RNA was isolated from samples harvested at regular intervals of 2-8 hours. 
Similar to previous experiments on in vitro-adapted isolates [21], these ex vivo samples displayed extensive stage specificity in transcriptional regulation during their 48-hour IDC (Additional file 3). However, in contrast to the in vitro conditions, the assembled ex vivo transcriptional profiles indicate considerable differences in the rates of stage progression (Figure 1a; Additional file 3). Using a Spearman-rank/Pearson correlation method, we identified a best fit of the "age" of each $e x$ vivo experimental point based on peak correlation values using the previously generated $P$. falciparum IDC transcriptome in vitro [22]. Here we observed that while at the time of blood collection, all parasite populations correspond to the ring stages (10-16 hours post invasion, hpi), the subsequent IDC development was subjected to significant fluctuations (Figure 1b). 5 out of

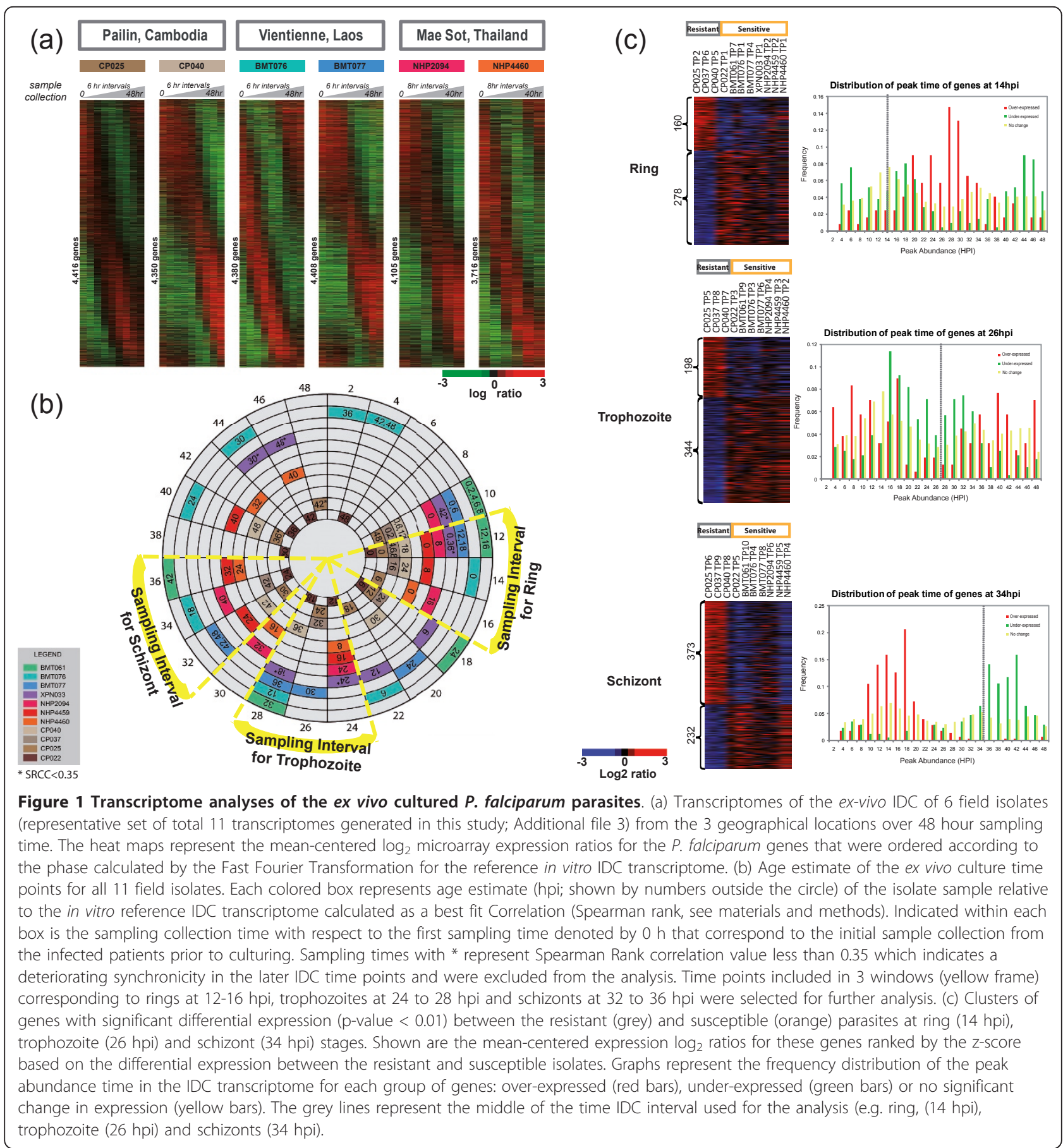


the 11 isolates (BMT061 and BMT077 from Laos, NHP2094 from Thailand and CP040 and CP037 from Cambodia) exhibited an initial developmental arrest in the ring stage for 16-24 hours post collection (Figure 1b). In spite of this initial arrest, these isolates reactivated their IDC progression and developed unidirectionally through trophozoite and schizont stages. The progress of the ex vivo cultured P. falciparum isolates through these later stages was also uneven. The most extreme example is the Lao isolate BMT077 that showed additional arrests in the trophozoite and early schizont stages at 30 to 48 hours post collection (Figure 1a and 1b). Overall, the developmental shifts in the IDC progression do not correlate with the site of collection, thus excluding the possibility of experimental bias due to culturing techniques in each field laboratory. These data support the previous observation of Lemiuex et al. (2008) who showed that the ages of 25 P. falciparum isolates cultured ex vivo for 48 hours fell into a large interval of 20-44 hpi [23]. In addition, the correlation coefficients between the mRNA profiles of field isolate time points and the in vitro control transcriptome are above 0.55 which demonstrates a good synchronicity of the ex vivo cultures (Additional file 4). Taken together, these data show that careful assessment of the parasite stage of development (age) at any experimental time point using a reference dataset is essential in ex vivo analyses of Plasmodium parasites.

To identify genes whose expression is associated with artemisinin resistance, we compared global transcription levels between the three artemisinin resistant isolates and the remaining sensitive isolates by analyzing steady state mRNA levels in 3 developmental stages; ring (12$16 \mathrm{hpi}$ : hours post invasion), trophozoite (24-28 hpi) and schizont (32-36 hpi) (Figure 1b). For that, we included the experimental time points that show highest correlation value to the in vitro reference transcriptome [22] within these sampling intervals (Figure 1b). Overall, we identified 160 (3.9\%), 198 (4.9\%) and $373(9.2 \%)$ genes that are up-regulated and 278 (6.9\%), 344 (8.5\%) and $232(5.7 \%)$ genes that are down-regulated in the resistant parasites ( $\mathrm{p}$-value $<0.01)$ at the ring, trophozoite and schizont stages, respectively (Figure 1c, Additional file 5). Interestingly, the majority of the genes over-expressed in the ring stage of the resistant parasites correspond to trophozoite- specific genes (peak mRNA abundance in the normal IDC) and the genes over-expressed in the schizont stages represent mainly ring and trophozoite specific transcripts (Figure 1c). The genes up-regulated in the trophozoite stage are evenly distributed between ring and schizont specific transcripts. This indicates that the transcriptional upregulations associated with artemisinin resistance constitute either accelerated timing of transcription of trophozoite and schizont genes at the ring stage, or prolonged expression of ring and trophozoite transcripts in the schizont stage. Intriguingly, this pattern was not observed for down-regulated genes whose expression in artemisinin resistant parasites coincides with their expected stage specificity, albeit at lower levels than expected in the artemisinin sensitive isolates (Figure 1c). Taken together, these results suggest that artemisinin resistance is associated with specific modifications of the IDC transcriptional cascade that involve a large number of genes and presumably alter the levels and temporal distributions of biological and cellular functions.

\section{Functional analysis of artemisinin resistance associated genes}

To evaluate the physiological relevance of the identified differential gene expression, we utilized Gene Set Enrichment Analysis (GSEA) [24] to explore functional assignments of genes associated with artemisinin resistance (Figure 2; Additional file 6). We found that genes down-regulated at ring and trophozoite stages represent well established biochemical and cellular pathways such as glycolysis, pentose phosphate shunt, REDOX, nucleotide and glutathione synthesis, and the TCA cycle (Figure $2 \mathrm{a}, \mathrm{b})$. Under normal growth, these pathways reach transcriptional peaks during the early stages of the IDC, so down-regulation indicates reduced expression in young parasites. In addition, we observed a significant down-regulation of genes associated with DNA replication and protein degradation in the trophozoite and schizont stages (Figure 2a, b; Additional file 6, 7). This down-regulation may represent a delayed onset of expression that normally starts during at the ring/trophozoite transition. At the schizont stage, the artemisinin resistant parasites were characterized by marked over-expression of genes that belong to many pathways associated with protein synthesis, folding and trafficking (Figure 2a, b). These include genes involved in ribosome assembly and maturation, chaperone-assisted protein folding, translational initiation and elongation (Additional file 6, 7). In addition, we observed up-regulation of several additional pathways such as RNA metabolism and hemoglobin degradation, both of which could contribute to increased capacity of protein synthesis in these parasites by boosting global levels of RNA transcripts and concentration of amino acids produced by the food vacuole (Additional file 6, 7). Investigating individual genes in the affected pathways, we observed that while in some cases the differential expression affects most genes (such as glycolysis or REDOX), in other pathways (such as translational initiation or proteasome degradation), only a fraction of genes exhibit differential expression (Additional file 8). These latter genes may 


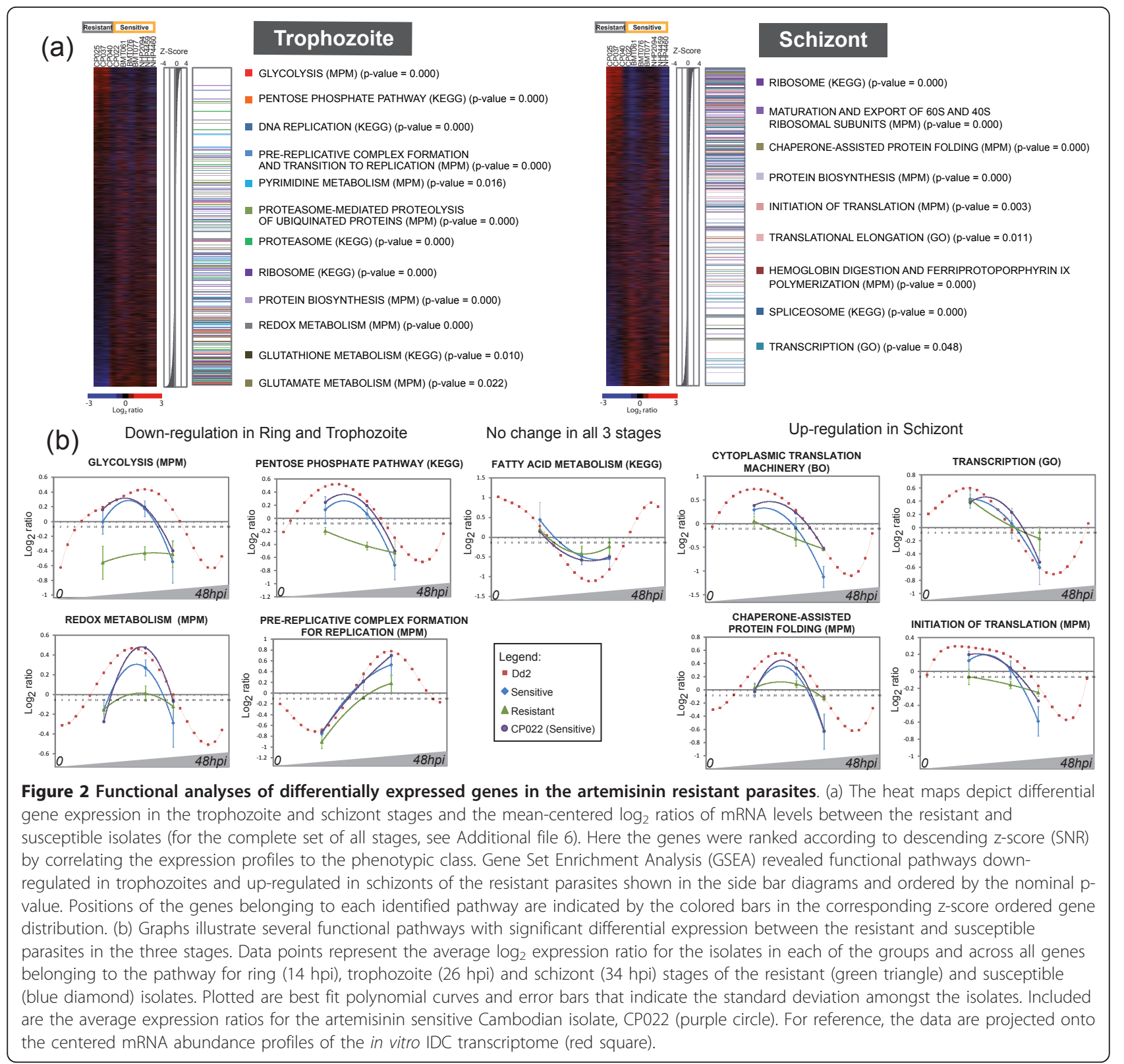

represent crucial regulatory or rate limiting steps in these biological processes.

In summary, our data suggest that the specific modulation of the IDC transcriptional cascade observed in artemisinin resistant parasites has at least two major physiological implications that include: down-regulation of metabolic and cellular pathways in the first half of the IDC (up to $28 \mathrm{hpi}$ ) and prolonged transcription upregulation of functionalities associated with protein synthesis and their supporting activities in the late stages ( $\sim 36 \mathrm{hpi})$. Interestingly, this transcriptional program was observed in all three Western Cambodian isolates with the delayed clearance but not in the isolate collected in the same region (CP022) that had a normal clearance time (Figure 2b; Additional file 7). This suggests that the altered transcriptional pattern is not a simple reflection of geographical or other generic differences between P. falciparum isolates but is indeed associated with artemisinin resistance.

\section{Differential expression of regulatory proteins may contribute to artemisinin resistance}

Artemisinin resistance in Western Cambodia was shown to exhibit a genetically inheritable pattern [20]. Thus it is feasible to speculate that the broad transcriptional changes associated with this phenotype may have 
resulted from a small number of genetic mutations in key regulatory proteins such as global transcription factors, chromatin remodeling-associated proteins or cell cycle regulators. We sought to explore the transcriptional data to find further clues for such underlying genetic determinants. For that, we inspected the genes whose expression was changed consistently in the three individual stages as these may be linked with a putative genetic variation (possibly in their regulatory elements). To identify such genes, we determined the rank product score for differentially expressed genes and classified them based on their differential expression in all 3 stages (Figure 3a; Additional file 5). Interestingly, the rank distribution was skewed towards lower values where larger numbers of genes show lower than expected rank scores (Figure 3a). This indicates that there are more genes consistently down-regulated in the artemisinin resistant parasites in all three stages compared to the up-regulated genes that tend to be overexpressed in only one or two of the IDC developmental stages.

Functional enrichment analyses of the top 5\% of genes from both extremes of the distribution (see Figure 3a grey boxes) did not uncover any additional functional groups compared to the stage-wise GSEA (Figure 2), however, visual inspection of these gene groups identified 41 putative transcription regulators, of which 22 are under-expressed and 19 are over-expressed. These include transcription factors, RNA binding proteins, cell cycle regulators, chromatin remodeling associated (a)

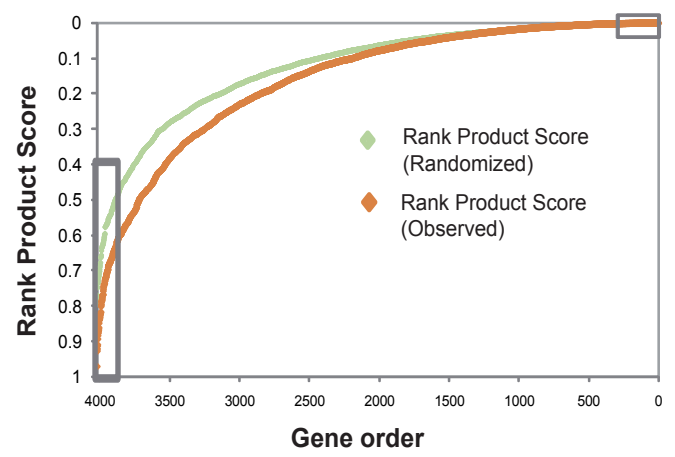

(c)
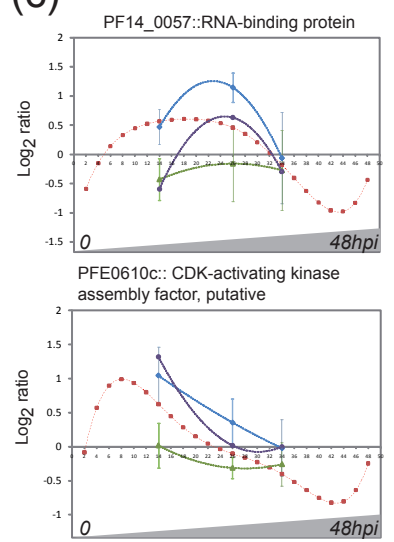

(b)

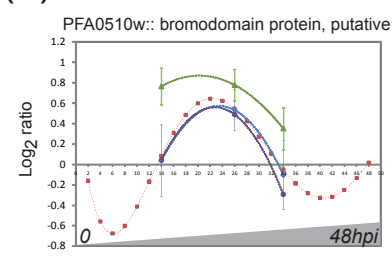

PF14_0350:: N-acetyltransferase (HAT), putative

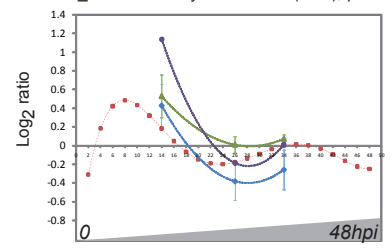

(d)

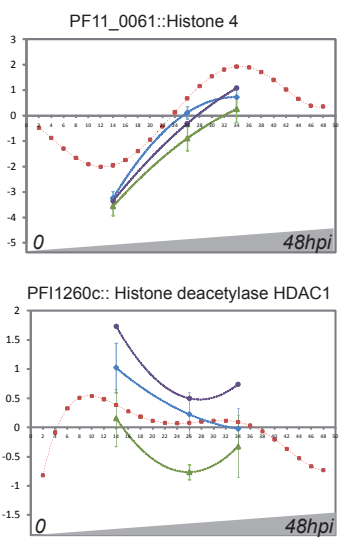

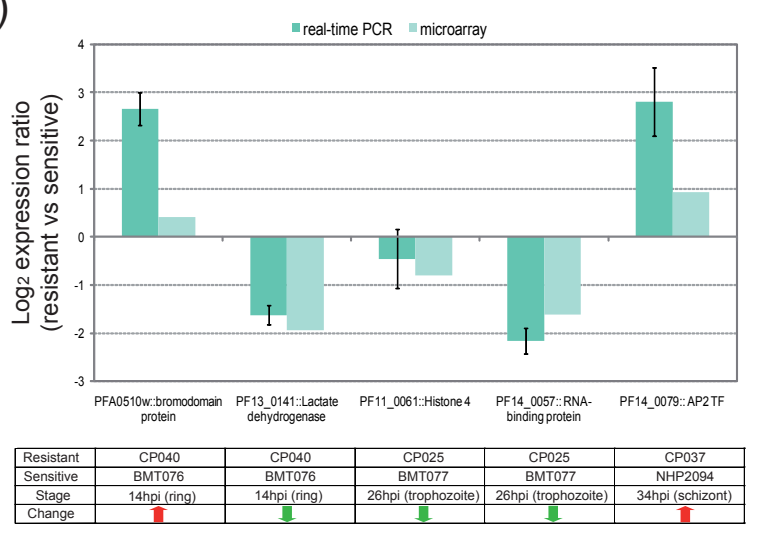

Figure 3 Classification of differentially expressed genes across the whole IDC and validation of differential expression of 5 genes by qPCR. (a) Plot of the Ranked Product Score for all 4,015 genes calculated from the geometric mean of the ranked z-scores of the genes in the 3 stages in the generated transcriptome (orange) and in the randomized dataset (green) (for details see material and methods). The graphs represent 4 over (b) and 4 under-expressed (c) genes in the resistant parasites with potential regulatory functions present in the top 5\% of each extreme of the rank product distribution, respectively ((a) grey boxes). Data points represent the mean log ${ }_{2}$ expression ratios of the genes in the resistant (green triangle), susceptible Lao and Thai (blue diamond), and susceptible Cambodian isolates (CP022, purple circle) across the three selected stage intervals. The data are projected onto the gene expression profiles analyzed by the in vitro IDC transcriptome (red square). Error

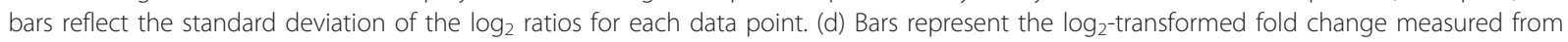
relative quantification of a resistant versus a sensitive isolate using PFC0965w as a reference control gene in real-time PCR experiments (teal) and plotted alongside the microarray expression ratios (light blue). Error bars reflect the standard deviation of the log 2 ratios over triplicates. 
proteins, histone modification enzymes as well as histones (Figure 3b, c, for complete list see Additional file 5 Sheet "Rank product score"). The most remarkable examples are strong down-regulation of genes coding for histone deacetylase 1 protein (HDAC1) (PFI1260c), recently proposed to play a major role in the transcriptional regulation [25], and CDK-activating kinase assembly factor (PFE0610c) whose paralogue was shown be associated with HDAC1 in P. falciparum [26]. Also, the artemisinin resistant parasites show a considerable upregulation of the AP2 containing transcription factor (PF14_0079), bromo-domain containing protein (PFA0510w), putative histone acetyltransferase (hat; PF14_0350), zinc finger protein (PF14_0416), and the $P$. falciparum homologue of yeast histone chaperone Rttp106-like transcriptional regulator (PFE0870w). In addition to these DNA interacting regulatory proteins, we identified 10 genes encoding the RNA-recognition motif (RRM) that are involved in regulating mRNA stability or translational repression. Quantitative real-time PCR carried out with 4 of these genes (PFA0510w, PF14_0079, PF11_0061 and PF14_0057) further confirmed that these genes are significantly differentially expressed between the resistant and sensitive isolates (Figure 3d). Differential expression of these genes encoding regulatory factors may contribute to the global changes in the transcriptome observed in the artemisinin resistant parasites.

\section{Copy number variations (CNV) and genotypes of artemisinin resistant isolates}

Several recent studies have demonstrated a frequent occurrence of gene copy number variants $(\mathrm{CNV})$ in $P$. falciparum and linked these to differential gene expression in field isolates and laboratory strains [27-32]. This can contribute to the variability in drug sensitivities observed among isolates [33,34]. We carried out comparative genomic hybridizations with genomic DNA of the four Cambodian and two Lao isolates and demonstrated that CNV profiles exhibit a clear segregation between these two groups (Figure 4a). Among the 138 genes occurring within the $93 \mathrm{CNV}$ detected segments are Histone 4, GTP cyclohydrolase I (pfgch1), hyp 4/5 exported proteins, phist genes and Maurer's cleft two transmembrane proteins (pfmc-2tm) [27-32]. Increased copy number of $p f g c h 1$ has been previously linked with resistance to antifolate antimalarial drugs and its amplification in the Cambodian isolates ( $\mathrm{p}$-value $=0.002$ ) may reflect the prolonged use of these drugs in this region [35]. Other newly identified CNVs include several hypothetical genes; an autophagocytosis associated protein and $\mathrm{Zn}^{2+} / \mathrm{Fe}^{2+}$ permease (data not shown). Overall we observed strong similarities amongst the Cambodian isolates, however none of the identified CNV could be associated with artemisinin resistance. This genetic coherence among the four Cambodian isolates contrasts with their transcriptional heterogeneity and indicates that copy number differences are strongly associated with differentiation in geographical origins. More genetic studies with large number of isolates will be required to assess the role of CNVs in artemisinin resistance.

In addition to the CGH analysis, we carried out "standard" genotyping of genes coding for merozoite surface proteins: $m s p 1, m s p 2$ and glutamate-rich protein: glurp together with sequencing of drug-resistant markers: multidrug resistant protein 1 (pfmdr1) and dihydropteroate synthase (pfdhps). This analysis revealed that the four Cambodian and two Lao isolates are genetically distinct from each other carrying different alleles of the tested genes (Figure 4b). Of these, CP025 and CP037 appeared highly related, exhibiting identical $m s p 1$ and msp 2 nested PCR products of $\mathrm{KO} 33$ and $\mathrm{IC} / 3 \mathrm{~d} 7$ alleles (Figure 4b). However, these two isolates differ in 2 nonsynonymous SNPs of codons K214Q and K1181T and a synonymous SNP in codon 171 in the $p f m d r 1$ gene (Figure 4c). In addition, CP025 and CP037 exhibit subtle differences in their $\mathrm{CNV}$ pattern as measured by $\mathrm{CGH}$ (Figure 4a). Interestingly, we found that none of the 6 isolates carry the N86Y pfmdr1 mutation (Figure 4c) whose presence is frequent in many Southeast Asian regions [36] and which is commonly associated with chloroquine resistance and mefloquine hypersensitivity [37]. Furthermore, we observed significant haplotype sharing amongst analyzed isolates such as CP040 and CP022 that share the "NEFSNVD" haplotype of pfmdr1, containing the non-synonymous Y184F mutation. Moreover, CP025, CP037, CP040, CP022 and XPN003 share the IAGEAA haplotype of $p f d h p s$ with non-synonymous triple mutants S436A, G437A and K540E, which were previously linked to resistance to sulfadoxine-pyrimethamine [38,39]. The mutations in dhps may reflect the selection pressure as a result of an extensive antifolate drug use in this region over several decades. In summary, these genetic studies suggest that while the Western Cambodian isolates are not identical isogenic clones, they share a recent common ancestor that is evident from their CNV profiles. Hence, the highly unique and also uniform CNV pattern identified in these parasites may represent a genetic background that contributes to development of artemisinin resistance and possibly other drug resistant phenotypes in this region.

\section{Discussion}

\section{Mechanism of artemisinin resistance}

Artemisinin resistance of $P$. falciparum is a major threat to malaria control. Understanding its molecular basis is thus essential for determining treatment strategies, 


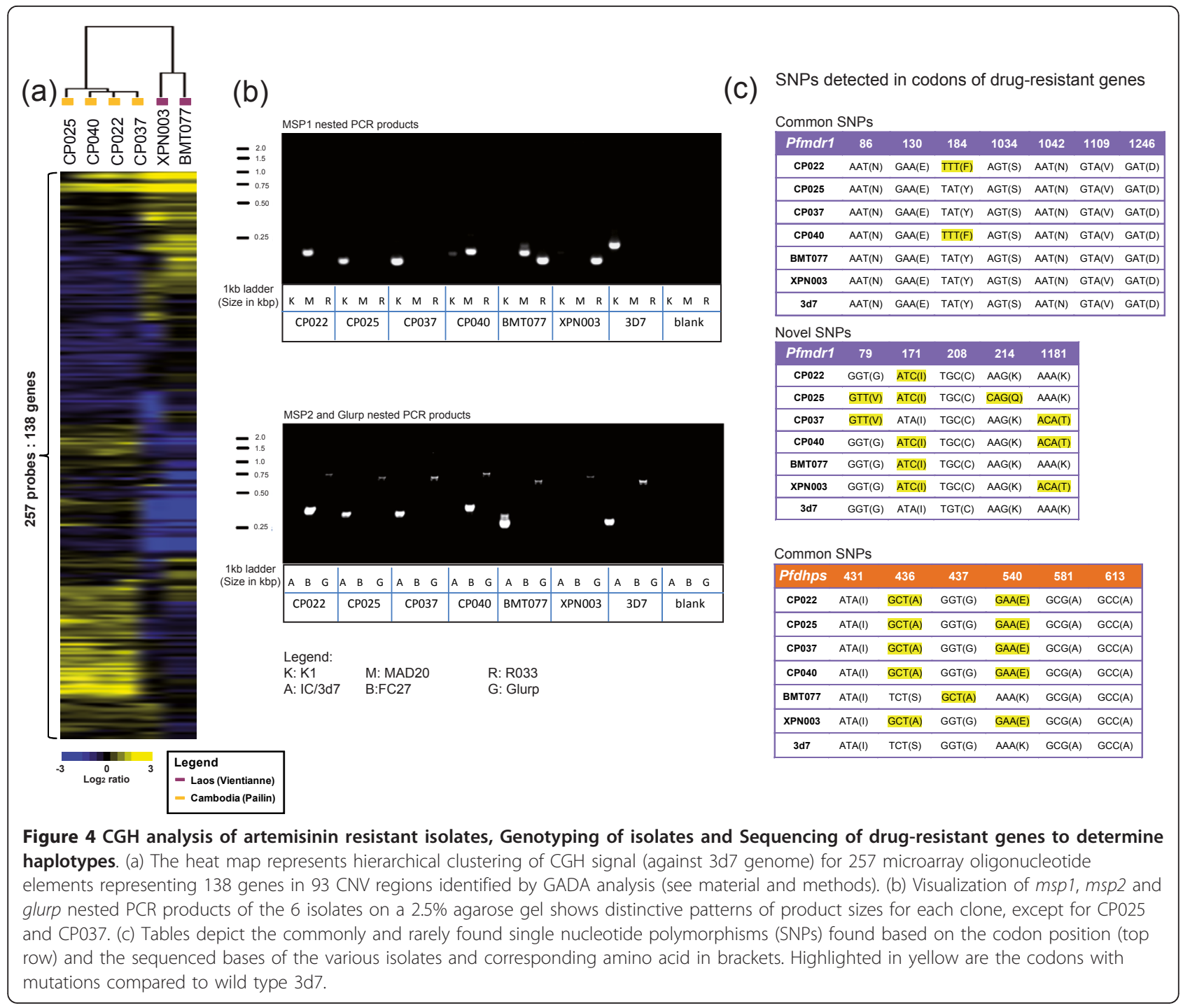

mapping the spread of resistance and guiding elimination [20,40-44]. Mutations or amplification of genes encoding transporters or target enzymes have been identified as resistance mechanisms to other antimalarial drugs. It is possible that resistance to artemisinin is unlike these classical mechanisms in vitro but instead results from a complex series of genetic and epigenetic events affecting multiple pathways. Here we showed that artemisinin resistant parasites are characterized by a specific modulation of the IDC transcriptome that affects a broad spectrum of genes and biological functions. First, we detected a specific down-regulation of many ring stage-specific metabolic pathways such as energy metabolism, nucleotide synthesis etc. Second, the progress to mature schizont stages was marked by significant increase in transcription of genes associated with essentially all functionalities involved in protein metabolism (Figure 2). Based on these two observations, we propose a plausible model for molecular basis of the artemisinin resistance observed in these Cambodian isolates that is founded on two (possibly independent) events: (i) Limited metabolic activity of the ring stages could lead to lower levels of hemoglobin digestion, less ferrous ions produced and thus reduced activation and conversion of artemisinin drugs to reactive intermediates [45]. This effect may be linked to the high prevalence of hemoglobinopathies, especially Hemoglobin E and $\alpha$-thalassemia in this area conferring increased oxidant stress $[46,47]$. This is possibly compounded by decades of unregulated artemisinin use in Western Cambodia which may select for parasites with greater resistance to oxidant stress during the ring form development. Alternatively, the lower metabolic activities of the ring stages may be a prerequisite of the ability of the resistant parasite to become dormant under the artemisinin pressure as demonstrated by several in vitro 
analyses $[17,18]$. Although this phenomenon is unlikely to be the major factor in artemisinin resistance, it is worth noting that the results obtained in our study are in agreement with the transcriptional analyses of the in vitro derived artemisinin tolerant parasites that include mRNA levels of the hypoxanthine phosphoribosyl transferase (PF10_0121), a cell cycle regulator (PFE1415w) and a Heat Shock Protein 70 kDa (PF08_0054) (Additional file 9) [40]. (ii) The increased activity of protein metabolism may contribute to the resistance by withstanding the damaging effects of artemisinin on parasite's proteins by increasing rates of protein turnover and synthesis and thus compensate for loss of active proteins. This is consistent with the presumed artemisinin mode of action in which the drug inflicts substantial damage to the parasite cell either by an oxidative stress (via reactive free radicals) or by direct alkylation of a wide spectrum of cellular components such as proteins, heme, and lipids [48-53].

\section{Transcriptional regulation and artemisinin resistance}

It is important to note that the differences in mRNA levels linked to artemisinin resistance were not the most dramatic transcriptional differences detected among the field isolates. Functional enrichment analysis of genes that vary the most in their expression among the 11 field isolates irrespective of their artemisinin sensitivities, revealed a distinct set of functionalities that varied in gene expression amongst field isolates in general. These include mainly genes encoding proteins of host-parasite interactions, Maurer's clefts proteins, invasion-related proteins, as well as factors of fatty acid metabolism, glycolysis and hemoglobin digestion (Additional file 10). This indicates that the observed transcriptional differences between artemisinin resistant and sensitive strains may represent a new event in transcriptional differentiation of field isolates that does not occur in other parasite populations. Although very little is known about molecular factors of transcriptional regulation in P. falciparum, a number of previous studies [25,54-57] have indicated the existence of broad range regulatory mechanisms that affect large groups of genes controlling the progression of the Plasmodium life cycle. Although more studies that involve large epidemiological surveys followed by extensive molecular analyses will have to be carried out to support such putative mechanisms, here we explored genes whose expression was affected in all three developmental stages in the resistant Western Cambodian parasites. One of the most remarkable examples of consistently down-regulated genes is $p f h d a c 1$ and its putative interacting proteins partner CDK-activating kinase, both of which show dramatic down-regulation in all three developmental stages (Figure 3). In our recent study, we showed that HDAC activities play a highly dynamic role in regulating the transcriptome of the Plasmodium life cycle and that their inhibition leads to widespread transcriptional changes. Intriguingly, the transcription profile of the resistant parasites is reminiscent of the effect of HDAC inhibitors on the P. falciparum gene expression in which most gene induction represent accelerated transcription in the ring and trophozoite stages and prolonged mRNA expression during the schizont stage [25].

Another gene whose differential expression is significant is histone 4 (PF11_0061). Histone 4 is the only nucleosomal subunit present as a single copy gene and thus its down-regulation could have severe implication on the nucleosomal assembly during the $P$. falciparum schizont stage. Depletion of histone 4 in both yeast and human cells causes an arrest or dramatic delay in the progression of the S-phase, which is caused by insufficient nucleosomal assembly and subsequently inhibition of DNA synthesis $[58,59]$. We observed a modest but statistically significant decrease of histone 4 in the artemisinin resistant $P$. falciparum parasites (Figure 3d) that could analogously lead to a delayed onset of schizogony and thus prolonged expression of genes associated with the typical trophozoite functions such as protein synthesis and hemoglobin digestion (Figure 2). Since the $\mathrm{CNV}$ profiles were similar among the four Cambodian isolates regardless of their tolerance level to artemisinin, more studies will be needed to understand their role in regulating transcriptional levels in artemisinin resistant parasites. More importantly, the coherence of CNV profiles among the Cambodian isolates indicates that the parasites in this region share a recent common ancestor. Similar conclusion was made by an admixture study carried out in Southeast Asia that demonstrated a subgroup of recently expanded parasite populations in Western Cambodia [60]. This could be a result of intense administration of a successive number of antimalarials from chloroquine to mefloquine to sulfodoxine-pyrimethamine to treat malaria cases in the Western Cambodian region over the last 80 years. It is plausible that a population with a restricted genotype has emerged with a genetic background that has higher propensity to give rise to resistance of the $P$. falciparum parasites to artemisinin.

\section{Conclusions}

Here we present the most comprehensive transcriptional analysis of the artemisinin tolerant malaria parasites collected at the site of its origin, Western Cambodia. Although much more extensive research on multiple levels will be needed to elucidate the complete mechanism, the results from these studies provide the first testable hypotheses regarding both the global pattern of the transcriptional cascade and candidate genes involved in artemisinin resistance. 


\section{Methods}

Sample collection from patient and during ex-vivo IDC

On admission to the hospital and upon consent, $10 \mathrm{ml}$ of total infected blood was taken from each adult P. falciparum-infected patient from the various field sites (Pailin, Cambodia; Xepon, Savannakhet Province, Laos; Mae Sot, Thailand). Samples were filtered by CF11 column purification to remove white blood cells and obtain infected red blood cells which were subjected to in vitro culture for one generation of the IDC over 48 hours. For every isolate, a total of 6 to 10 samples were harvested at regular intervals of 2 to 8 hours throughout the IDC. 100-500 $\mu$ l of packed red blood cells with $1 \%$ $10 \%$ parasitemia were collected per time point sampling.

\section{RNA extraction, cDNA synthesis \& Microarray Hybridizations}

Total RNA was isolated from all ex-vivo samples using the trizol-chloroform-isopropanol precipitation method as described [21]. Synthesis of target DNA for microarray hybridization was carried out as previously described $[27,61]$ with the following exceptions: Reverse-transcription was carried out using 200 units of SuperScript II enzyme (Invitrogen, USA) to create the first strand cDNA. Following PCR amplification with 19 cycles and purification of the product, a total of 5-7_g of doublestranded DNA was obtained for each sample. From this, $4 \mu \mathrm{g}$ of DNA was labeled with fluorescent Cy5 dye and used for the microarray hybridization (GE Amersham, USA). For the reference pool, cDNA consisting of all IDC stages of $3 \mathrm{~d} 7$ strain was made identically and labeled with $\mathrm{Cy} 3$ dye. Equal amounts of labeled sample from each time point and reference RNA pool was hybridized on the 70-mer P. falciparum cDNA microarray chip containing 10,680 oligonucleotides representing 5,343 coding genes [62]. The microarray hybridization was carried out at $65^{\circ} \mathrm{C}$ in the automated MAUI hybridization system (BioMicro Systems, USA). The microarray chips were scanned using the GenePix 4000 B scanner and GenePix Pro 6.0 software (Molecular Devices, USA).

\section{Microarray data Processing and analysis}

The initial acquired microarray data was filtered to include microarray hybridization "spots" with at least 95\% pixels having signal intensity above 2 standard deviations from background for both Cy3 and Cy5 fluorescence intensity. Subsequently, array Lowess normalization was applied to all arrays as implemented by Acuity 4.0 software (Molecular Devices, USA). The assembly of the IDC transcriptome for all isolates was carried out using Fast Fourier Transform as previously described [21] with following modifications; the expression value for each gene is represented by an average value obtained from all oligonucleotide probes in each transcript/gene. To construct the phaseogram of reference IDC transcriptome for further comparisons, genes with expression data in at least 19 out of 24 (80\%) time points were extracted, any missing values were imputed and polynomial fit of order 6 was applied to generate smoothed data. This was then analyzed by Fast Fourier Transform method and all 4,634 genes with the meancentered gene expression $\log _{2}$ ratios were sorted according to phase from $-\pi$ to $\pi$ (Additional file 2 ). The phaseogram of each isolate contains mean-centered gene expression data ordered according to the phase value. For each isolate's time course, only genes having at least $80 \%$ of data present were extracted and any missing data values were imputed by $\mathrm{KNN}\left(\mathrm{K}^{\text {th }}\right.$ nearest neighbor) method using $\mathrm{R}$ version 2.10.1 package and impute function.

\section{Mapping parasite's sample age to the reference IDC}

To map the age of each isolate time point sample relative to the progression of in vitro lab strain IDC, Spearman Rank Correlation Coefficient (SRCC) values between global mRNA profiles for each isolate time point and time points in the reference IDC transcriptome [22] (every 2 hour sample time point of the in vitro Dd2 lifecycle) were calculated. The stage (hpi) corresponding to the peak SRCC value was assigned as the best estimate of the age of the parasite for that sample collection (see colored box in Figure 1b). Only samples which had SRCC above a value of 0.35 were considered in the following analysis. To select time points for downstream differential analysis, we calculated the frequency distribution of isolate time points found within a window of three consecutive hpi and selected three windows based on the highest representation of isolates with at least one sampling time point found within that window. Isolates with sample time points found within the 4 hour windows of $12-16 \mathrm{hpi}, 24-28 \mathrm{hpi}$ and 32-36 hpi corresponding to mid-ring, early-trophozoite and early-schizont stages were grouped accordingly as representing these stages.

\section{Identifying Differentially Expressed Genes}

$\mathrm{Z}$ scores were calculated by correlating the average gene expression to noise ratio (SNR) of the mRNA expression ratios to the clearance phenotype (ie. resistant - CP025, CP037, CP040 vs. sensitive - CP022, ВMT061, ВMT077, BMT076, XPN003, NHP2094, NHP4459, NHP4460) and normalized to sample size.

$$
Z=\sqrt[2]{N} \cdot \frac{\mu_{a}-\mu_{b}}{\sigma_{a}+\sigma_{b}}
$$


Where $\mu_{a}$ and $\mu_{b}$ are the mean expression $\log _{2}$ ratio of resistant and sensitive parasites respectively and $\sigma_{a}$ and $\sigma_{b}$ are the standard deviations of resistant and sensitive group respectively. Differentially expressed genes were defined with $\mathrm{p}$-value cut-off $<0.01$ from Student $\mathrm{t}$ - distribution of the z-scores carried out for the 3 stages. Gene set enrichment analysis [24] was carried out on the resistant vs. sensitive parasites using SNR. A total of 1,261 gene sets comprising of KEGG pathways [63], MPM and functional groups based on previous studies [21,64-66] were included. Nominal p-value and false discovery rate (FDR) were calculated for each gene set from the observed normalized enrichment score (NES) against a null distribution using a gene set-based permutation test. Gene sets with p-value $<0.05$ and FDR $<$ $25 \%$ were considered to be statistically significant.

\section{Calculate Timing of Peak mRNA abundance of genes}

The time of peak expression for each gene (represented by hpi) is derived from the phase of the Fourier transformation of the in vitro reference transcriptome using the formula:

$$
\text { Peak Abundance Time }(h p i)=2+\left[\frac{46(\theta+\pi)}{2 \pi}\right]
$$

Where $\theta$ is the phase value of the gene.

\section{Calculation of Rank Product Score}

Using the z-scores (see above) of each gene, we sorted the genes according to descending order and assigned a numerical rank score for every gene at each of the three stages. In order to generate a list of genes consistently up/down-regulated in the three stages, we calculate the geometric mean of the rank score to determine the rank product (RP) score of each gene using the formula:

$$
R P_{\mathrm{g}}=\left[\operatorname{rank}_{\mathrm{g}}{ }^{14 \mathrm{hpi}} \times \operatorname{rank}_{\mathrm{g}}{ }^{26 \mathrm{hpi}} \times \operatorname{rank}_{\mathrm{g}}{ }^{34 \mathrm{hpi}}\right] / \mathrm{N}^{3}
$$

Where the $\operatorname{rank}_{\mathrm{g}}{ }^{14 \mathrm{hpi}}, \operatorname{rank}_{\mathrm{g}}{ }^{26 \mathrm{hpi}}, \operatorname{rank}_{\mathrm{g}}{ }^{34 \mathrm{hpi}}$ corresponds to the rank score of the gene at $14 \mathrm{hpi}, 26 \mathrm{hpi}$ or 34 hpi respectively.

\section{Copy Number Difference Analysis}

To identify significant CNVs among the 6 isolates, we performed comparative genomic hybridization using genomic DNA extracted from the isolates (CP022, CP025, CP037, CP040, BMT077, XPN003) against genomic DNA of the reference lab strain of $3 \mathrm{~d} 7$ as previously described [27]. We carried out subtraction analysis between any 2 isolates in multiple pair-wise comparisons and considered only segments that have at least 1.7 -fold change in mean amplitude and $\mathrm{T}$-coefficient greater than 3.5 in minimum 2 consecutive gene probes between any 2 isolates as significant. This was performed using the Genomic Alteration Detection Analysis (GADA) program in $\mathrm{R}$ package [67].

\section{Real-time PCR (qPCR)}

Real time PCR and the relative quantification of gene expression was performed in at least triplicates using the comparative CT method of calculating $-\Delta \Delta \mathrm{Ct}$ values and taking PFC0965w as a reference control gene, as previously described [62].

\section{Genotyping of isolates and Sequencing of pfmdr1 and pfdhps genes}

Genotyping of $m s p 1, m s p 2$ and glurp were carried out as previously described [68] with positive control of lab clone, $3 \mathrm{~d} 7$, in a nested PCR reaction and products were visualized on a $2.5 \%$ agarose gel. Nested PCR reactions were performed as previously described [69] to generate fragments of $m d r 1$ and $d h p s$ genes containing commonly found SNPs and products were sequenced with corresponding forward and reverse primers using ABI Big Dye Terminator cycle sequencing method.

\section{Additional material}

Additional file 1: Parasite density over course of treatment and treatment outcomes. Plot of the parasite densities (relative to starting parasite numbers on admission) from the time of patient's $1^{\text {st }}$ admission date up to 100 hours after admission. Of the 4 isolates from Pailin, Cambodia, only 3 (CP025 (red), CP037 (green), CP040 (blue)) display significant delayed parasite clearance time (pct) of 78 and 96 hours from the patients after treatment while CP022 (purple) parasites was cleared earlier at 54 hours after treatment. The initial parasite numbers upon admission (para0) and parasite reduction ratio at 24 hours (prr24) and 48 hours (prr48) are included in the table. Artesunate and mefloquine treatment regimes administered to the patients are listed (box).

Additional file 2: Information about the sampling times, parasitemia of the ring, trophozoite and schizont stages of the 11 isolates. na: information not available.

Additional file 3: Ex-vivo transcriptomes generated of the $11 \mathrm{P}$. falciparum field isolates from South East Asia. Transcriptomes of the ex-vivo IDC of all 11 field isolates from the 3 geographical locations measured over 48 hour sampling time. Only genes with at least $80 \%$ of time points with a positive signal were included for each of these transcriptomes. The phaseograms were constructed by ordering the mean-centered $\log _{2}$ microarray expression ratios to the genes ordered by phase calculated from the Fast Fourier Transformation of the Dd2 reference in vitro lifecycle.

Additional file 4: Distribution of Pearson correlations between all isolates for the $\mathbf{3}$ stages. Including isolate time points that correspond to the 3 stages - 14 hpi, 26 hpi and 34 hpi - graphs shown are average Pearson Correlations calculated from multiple pair wise comparisons between all isolates (graphs on left panel) and the average of the PCC for the resistant and sensitive parasites (graphs on right panel) at $14 \mathrm{hpi}$ (a), at 26 hpi (b) and at $34 \mathrm{hpi} \mathrm{(c).} \mathrm{Error} \mathrm{bars} \mathrm{represent} \mathrm{the} \mathrm{standard}$ deviation of all the pair-wise comparisons.

Additional file 5: Sheets 1-3 lists $\log _{2}$ expression data of all genes for the isolates grouped by ring (14 hpi), trophozoite (26 hpi) and schizont (34 hpi) stage and their corresponding z-scores (signal to noise) and p-values using student t-distribution. Genes with significant difference in expression between the resistant and sensitive 
isolates ( $p$-value $<0.01$ ) are highlighted in orange. Sheet "rank product score" lists all genes including putative transcriptional regulators (including those with zinc finger, bromodomain, etc., domains predicted by PFAM, Histone/HDAC/HAT-related, AP2-domain containing and potential cell cycle regulators) used in the analysis and their corresponding z-scores and rank product scores for ring (14 hpi), trophozoite (26 hpi) and schizont (34 hpi) stages.

Additional file 6: Functional analyses of differential expression in all stages of the artemisinin resistant parasites. For each of the 3 stages, genes were ranked according to the $z$-score by correlating the expression profiles to the phenotypic class. The mean-centered $\log _{2}$ ratios for each gene of the resistant (CP025, CP037, and CP040) and sensitive (CP022, BMT061, BMT076, BMT077, XPN003, NHP2094, NHP4459, NHP4460) isolates are represented in these clusters. Gene Set Enrichment Analysis [24] of the ranked clusters gave rise to gene sets downregulated in rings and trophozoites and up-regulated in schizonts in the resistant parasites as shown ordered by the nominal $p$-value, false discovery rate (FDR) q-value and Normalized Enrichment Score (NES). Significant gene sets were based on cut-off p-value of 0.05 and FDR qvalue of 0.25 .

Additional file 7: Functional pathways with significant differential expression in rings, trophozoites and schizonts of artemisinin resistant and sensitive parasites. Gene sets (functional groups) which are denoted in the graphs are obtained from various data sets of previous studies $[63,66,70]$ and plotted are all pathways that are significantly differentially expressed in artemisinin resistant parasites in at least one IDC stage. For each pathway, each data point at ring (14 hpi), trophozoite (26 hpi) and schizont (34 hpi) of the resistant (green triangle) and sensitive (blue diamond) series was calculated from taking the average of the expression $\log _{2}$ ratio of a gene across all isolates in that phenotypic group (resistant or sensitive) and then averaged for all the genes associated with that pathway. Best fit polynomial curves were plotted (lines). Error bars indicate the standard deviation among the isolates for that pathway. Included separately are the average expression ratios of all genes belonging to that pathway for CP022 isolate (purple circle) from Pailin, Cambodia and reference in vitro strain (red square).

Additional file 8: Relative expression of individual genes associated with four functional pathways that have significant differential expression in artemisinin resistant parasite. Top: Example of four functional gene sets with significant differential expression between resistant and sensitive parasites and the relative gene expression of all members of the gene sets at the three stages. Each set of data points are the average $\log _{2}$ expression ratios of the isolates in a group and averaged for all the genes in that pathway at 14,26 and $34 \mathrm{hpi}$. The curves are the best fit polynomial curves to the data points. Bottom: Each of the 3 graphs plotted depict the average $\log _{2}$ gene expression ratios of the isolates in the resistant (green triangle) or sensitive (blue diamond) group with the standard deviation represented by error bars in each particular pathway at 14,26 or 34 hpi.

Additional file 9: Transcriptional profiles of the 3 genes in the artemisinin resistant parasites compared with previous data published [18]. The mean expression $\log _{2}$ ratio (data point) and SD (error bars) among the resistant (green triangle) and sensitive (blue diamond) isolates for each stage are plotted for the genes: PF10 0121 hypoxanthine phosphoribosyltransferase (rank 3207/4029; p-value $=0.1$ ), PF08_0054 - Heat Shock Protein $70 \mathrm{kDa}($ rank 14/4041; p-value $=0.0004)$ and PFE1415w- cell cycle regulator (rank 3837/4041; $p$-value $=0.01$ ). The polynomial represents the best fit curve through the data points. The arrow indicates the approximate stage in which significant increased or lowered expression was observed in artesunate-tolerant parasites and the fold change [18] (Witkowski et al., 2010).

Additional file 10: Functional analysis and clustering based on general differences in gene expression among field isolates without phenotypic classification. (a) Clusters are represented by the $\log _{2}$ expression ratios for all genes ordered according to the standard deviation (SD) for each gene in a descending manner. GSEA [24] performed on this pre-ranked list of genes identified these functional gene sets as differentially expressed among field isolates without any phenotypic classification for the 3 stages. (b) Hierarchically clustered isolates for the genes showing greatest variation in expression ratios (taking genes with SD value at the $95^{\text {th }}$ percentile cut off). Each color denotes the location: Laos, Mae Sot or Pailin that the isolates originate from. The raw data reported in this paper has been deposited in the NCBI's Gene Expression Omnibus database [71] and are accessible through GEO Series accession number GSE25883. http://www.ncbi.nlm. nih.gov/geo/query/acc.cgi?acc=GSE25883

\section{List of abbreviations used}

IDC: Intra-erythrocytic developmental cycle; hpi: hours post invasion; PCT: Parasite clearance time; SRCC: Spearman rank correlation coefficient; PCC: Pearson correlation coefficient; SNR: Signal to noise ratio; NES: Normalized enrichment score; GSEA: Gene set enrichment analysis; KEGG: Kyoto Encyclopedia of Genes and Genomes; MPM: Malaria metabolic pathway maps; GO: Gene Ontology; CNV: Copy number variants; PCR: Polymerase chain reaction; SNP: Single nucleotide polymorphism

\section{Acknowledgements}

Maniphone Khanthavong, Odai Chanthongthip, Samlane Phompida, Tiengkham Pongvongsa, and Sengchanh Koumphiengmaniseng for their technical help and support. This work was supported by grant of the Singapore National Medical Council (NMRC) \# IRG10may058.

\section{Author details}

${ }^{1}$ School of Biological Sciences, Nanyang Technological University, Singapore. ${ }^{2}$ Department of Molecular Tropical Medicine and Genetics, Faculty of Tropical Medicine, Mahidol University, Thailand. ${ }^{3}$ Mahidol-Oxford Research Unit, Faculty of Tropical Medicine, Mahidol University, Thailand. ${ }^{4}$ KEMRIWellcome Trust Research Programme, Kilifi, Kenya. ${ }^{5}$ Wellcome Trust-Mahosot Hospital-Oxford University Tropical Medicine Research Collaboration, Mahosot Hospital, Vientiane, Lao People's Democratic Republic. ${ }^{6}$ Faculty of Postgraduate Studies and Research, University of Health Sciences, Vientiane, Lao People's Democratic Republic. ${ }^{7}$ Singapore Immunology Network, Biopolis, Agency for Science Technology and Research (ASTAR), Singapore. ${ }^{8}$ Centre for Clinical Vaccinology and Tropical Medicine, Churchill Hospital, Oxford, UK. ${ }^{9}$ The National Center for Parasitology, Entomology, and Malaria Control, Phnom Penh, Cambodia. ${ }^{10}$ Shoklo Malaria Research Unit, Mae Sot, Thailand.

\section{Authors' contributions}

MI, KC, NPJD, NJW, PRP, AMD and ZB designed research. SM, JS and KYL performed research. Ml organized field work. MI, MM, PNN, FN, BR, PY, DS, KC and AMD organized/provided sample collection. SM, MJM, RR and ZB analyzed data. SM and ZB wrote the paper. SM, MI, MJM, PRP, MM, PNN, FN, NPJD, NJW, AMD and ZB revised the manuscript. The authors declare that they have no conflict of interest. All authors read and approved the final manuscript.

\section{Received: 25 March 2011 Accepted: 3 August 2011}

Published: 3 August 2011

\section{References}

1. Nosten F, White NJ: Artemisinin-based combination treatment of falciparum malaria. Am J Trop Med Hyg 2007, 77:181-192.

2. White NJ: Qinghaosu (artemisinin): the price of success. Science 2008, 320:330-334

3. Mendis K, Rietveld A, Warsame M, Bosman A, Greenwood B, Wernsdorfer WH: From malaria control to eradication: The WHO perspective. Trop Med Int Health 2009, 14:802-809.

4. Bruce-Chwatt LJ: Malaria and its control: present situation and future prospects. Annu Rev Public Health 1987, 8:75-110.

5. Wellems TE: Transporter of a malaria catastrophe. Nat Med 2004, 10:1169-1171.

6. Wellems TE, Hayton K, Fairhurst RM: The impact of malaria parasitism: from corpuscles to communities. J Clin Invest 2009, 119:2496-2505.

7. Wongsrichanalai C, Pickard AL, Wernsdorfer WH, Meshnick SR: Epidemiology of drug-resistant malaria. Lancet Infect Dis 2002, 2:209-218 
8. Yang H, Liu D, Yang Y, Fan B, Yang P, Li X, Li C, Dong Y, Yang C: Changes in susceptibility of Plasmodium falciparum to artesunate in vitro in Yunnan Province, China. Trans R Soc Trop Med Hyg 2003, 97:226-228.

9. Huong NM, Hewitt S, Davis TM, Dao LD, Toan TQ, Kim TB, Hanh NT, Phuong VN, Nhan DH, Cong LD: Resistance of Plasmodium falciparum to antimalarial drugs in a highly endemic area of southern Viet Nam: a study in vivo and in vitro. Trans R Soc Trop Med Hyg 2001, 95:325-329.

10. Jambou R, Legrand E, Niang M, Khim N, Lim P, Volney B, Ekala MT, Bouchier C, Esterre P, Fandeur T: Resistance of Plasmodium falciparum field isolates to in-vitro artemether and point mutations of the SERCAtype PfATPase6. The Lancet 2005, 366:1960-1963.

11. Kachur SP, MacArthur JR, Slutsker L: A call to action: addressing the challenge of artemisinin-resistant malaria. Expert Rev Anti Infect Ther 2010, 8:365-366.

12. Noedl H, Se Y, Schaecher K, Smith BL, Socheat D, Fukuda MM: Evidence of artemisinin-resistant malaria in western Cambodia. N Engl J Med 2008, 359:2619-2620.

13. Carrara VI, Zwang J, Ashley EA, Price RN, Stepniewska K, Barends M, Brockman A, Anderson T, McGready R, Phaiphun L, Proux S, van Vugt M, Hutagalung $R$, Lwin KM, Phyo AP, Preechapornkul P, Imwong M, Pukrittayakamee S, Singhasivanon P, White NJ, Nosten F: Changes in the treatment responses to artesunate-mefloquine on the northwestern border of Thailand during 13 years of continuous deployment. PLOS One 2009, 4:e4551.

14. Lim P, Wongsrichanalai C, Chim P, Khim N, Kim S, Chy S, Sem R, Nhem S, Yi P, Duong S, Bouth DM, Genton B, Beck HP, Gobert JG, Rogers WO, Coppee JY, Fandeur T, Mercereau-Puijalon O, Ringwald P, Le Bras J, Ariey F: Decreased in vitro susceptibility of Plasmodium falciparum isolates to artesunate, mefloquine, chloroquine, and quinine in Cambodia from 2001 to 2007. Antimicrob Agents Chemother 2010, 54:2135-2142.

15. Dondorp AM, Nosten F, Yi P, Das D, Phyo AP, Tarning J, Lwin KM, Ariey F, Hanpithakpong W, Lee SJ, Ringwald P, Silamut K, Imwong M, Chotivanich K, Lim P, Herdman T, An SS, Yeung S, Singhasivanon P, Day NP, Lindegardh N, Socheat D, White NJ: Artemisinin resistance in Plasmodium falciparum malaria. N Engl I Med 2009, 361:455-467.

16. Saralamba S, Pan-Ngum W, Maude RJ, Lee SJ, Tarning J, Lindegardh N, Chotivanich K, Nosten F, Day NP, Socheat D, White NJ, Dondorp AM, White L: Intrahost modeling of artemisinin resistance in Plasmodium falciparum. Proc Natl Acad Sci USA 2011, 108:397-402.

17. Teuscher F, Gatton ML, Chen N, Peters J, Kyle DE, Cheng Q: Artemisinininduced dormancy in plasmodium falciparum: duration, recovery rates, and implications in treatment failure. J Infect Dis 2010, 202:1362-1368.

18. Witkowski B, Lelievre J, Lopez Barragan MJ, Laurent V, Su Xz, Berry A, Benoit-Vical F: Increased Tolerance to Artemisinin in Plasmodium falciparum Is Mediated by a Quiescence Mechanism. Antimicrobial Agents and Chemotherapy 2010, 54:1872-1877.

19. Nosten F: Waking the sleeping beauty. J Infect Dis 2010, 202:1300-1301.

20. Anderson Tim JC, Nair S, Nkhoma S, Williams Jeff T, Imwong M, Yi P, Socheat D, Das D, Chotivanich K, Day Nicholas PJ, White Nicholas J, Dondorp Arjen M: High Heritability of Malaria Parasite Clearance Rate Indicates a Genetic Basis for Artemisinin Resistance in Western Cambodia. The Journal of Infectious Diseases 2010, 201:1326-1330.

21. Bozdech Z, Llinas M, Pulliam BL, Wong ED, Zhu J, DeRisi JL: The transcriptome of the intraerythrocytic developmental cycle of Plasmodium falciparum. PLOS Biol 2003, 1:E5.

22. Foth BJ, Zhang N, Chaal BK, Sze SK, Preiser PR, Bozdech Z: Quantitative time-course profiling of parasite and host cell proteins in the human malaria parasite Plasmodium falciparum. Mol Cell Proteomics 2011.

23. Lemieux JE, Gomez-Escobar N, Feller A, Carret C, Amambua-Ngwa A, Pinches R, Day F, Kyes SA, Conway DJ, Holmes CC, Newbold Cl: Statistical estimation of cell-cycle progression and lineage commitment in Plasmodium falciparum reveals a homogeneous pattern of transcription in ex vivo culture. Proc Natl Acad Sci USA 2009, 106:7559-7564.

24. Subramanian A, Tamayo P, Mootha VK, Mukherjee S, Ebert BL, Gillette MA, Paulovich A, Pomeroy SL, Golub TR, Lander ES, Mesirov JP: Gene set enrichment analysis: a knowledge-based approach for interpreting genome-wide expression profiles. Proc Natl Acad Sci USA 2005, 102:15545-15550.

25. Chaal BK, Gupta AP, Wastuwidyaningtyas BD, Luah YH, Bozdech Z: Histone deacetylases play a major role in the transcriptional regulation of the Plasmodium falciparum life cycle. PLoS Pathog 2010, 6:e1000737.
26. Halbert J, Ayong L, Equinet L, Le Roch K, Hardy M, Goldring D, Reininger L, Waters N, Chakrabarti D, Doerig C: A Plasmodium falciparum transcriptional cyclin-dependent kinase-related kinase with a crucial role in parasite proliferation associates with histone deacetylase activity. Eukaryot Cell 2010, 9:952-959.

27. Mackinnon MJ, Li J, Mok S, Kortok MM, Marsh K, Preiser PR, Bozdech Z: Comparative transcriptional and genomic analysis of Plasmodium falciparum field isolates. PLOS Pathog 2009, 5:e1000644.

28. Dharia NV, Sidhu AB, Cassera MB, Westenberger SJ, Bopp SE, Eastman RT, Plouffe D, Batalov S, Park DJ, Volkman SK, Wirth DF, Zhou Y, Fidock DA, Winzeler EA: Use of high-density tiling microarrays to identify mutations globally and elucidate mechanisms of drug resistance in Plasmodium falciparum. Genome Biol 2009, 10:R21.

29. Cheeseman IH, Gomez-Escobar N, Carret CK, Ivens A, Stewart LB, Tetteh KK, Conway DJ: Gene copy number variation throughout the Plasmodium falciparum genome. BMC Genomics 2009, 10:353.

30. Kidgell C, Volkman SK, Daily J, Borevitz JO, Plouffe D, Zhou Y, Johnson JR, Le Roch K, Sarr O, Ndir O, Mboup S, Batalov S, Wirth DF, Winzeler EA: A systematic map of genetic variation in Plasmodium falciparum. PLOS Pathog 2006, 2:e57.

31. Jiang H, Yi M, Mu J, Zhang L, Ivens A, Klimczak L, Huyen Y, Stephens RM, Su XZ: Detection of genome-wide polymorphisms in the AT-rich Plasmodium falciparum genome using a high-density microarray. BMC Genomics 2008, 9:398.

32. Ribacke U, Mok BW, Wirta V, Normark J, Lundeberg J, Kironde F, Egwang TG, Nilsson P, Wahlgren M: Genome wide gene amplifications and deletions in Plasmodium falciparum. Mol Biochem Parasitol 2007, 155:33-44.

33. Uhlemann AC, McGready R, Ashley EA, Brockman A, Singhasivanon P, Krishna S, White NJ, Nosten F, Price RN: Intrahost selection of Plasmodium falciparum pfmdr 1 alleles after antimalarial treatment on the northwestern border of Thailand. J Infect Dis 2007, 195:134-141.

34. Price RN, Uhlemann AC, Brockman A, McGready R, Ashley E, Phaipun L, Patel R, Laing K, Looareesuwan S, White NJ, Nosten F, Krishna S: Mefloquine resistance in Plasmodium falciparum and increased pfmdr1 gene copy number. Lancet 2004, 364:438-447.

35. Nair S, Miller B, Barends M, Jaidee A, Patel J, Mayxay M, Newton P, Nosten F, Ferdig MT, Anderson TJ: Adaptive copy number evolution in malaria parasites. PLoS Genet 2008, 4:e1000243.

36. Price RN, Cassar C, Brockman A, Duraisingh M, van Vugt M, White NJ, Nosten F, Krishna S: The pfmdr1 gene is associated with a multidrugresistant phenotype in Plasmodium falciparum from the western border of Thailand. Antimicrobial Agents and Chemotherapy 1999, 43:2943-2949.

37. Mita T, Kaneko A, Hombhanje F, Hwaihwanje I, Takahashi N, Osawa H, Tsukahara T, Masta A, Lum JK, Kobayakawa T, Ishizaki T, Bjorkman A: Role of pfmdr1 mutations on chloroquine resistance in Plasmodium falciparum isolates with pfcrt K76T from Papua New Guinea. Acta Trop 2006, 98:137-144.

38. Enosse S, Magnussen P, Abacassamo F, Gomez-Olive X, Ronn AM, Thompson R, Alifrangis M: Rapid increase of Plasmodium falciparum dhfr/ dhps resistant haplotypes, after the adoption of sulphadoxinepyrimethamine as first line treatment in 2002, in southern Mozambique. Malar J 2008, 7:115.

39. Babiker HA, Al-Saai S, Kheir A, Abdel-Muhsin AMA, Al-Ghazali A, Nwakanma D, Swedberg G: Distinct haplotypes of dhfr and dhps among Plasmodium falciparum isolates in an area of high level of sulfadoxinepyrimethamine (SP) resistance in eastern Sudan. Infection Genetics and Evolution 2009, 9:778-783.

40. Witkowski B, Lelievre J, Lopez Barragan MJ, Laurent V, Su XZ, Berry A, Benoit-Vical F: Increased tolerance to artemisinin in Plasmodium falciparum is mediated by a quiescence mechanism. Antimicrob Agents Chemother 2010.

41. Imwong M, Dondorp AM, Nosten F, Yi P, Mungthin M, Hanchana S, Das D, Phyo AP, Lwin KM, Pukrittayakamee S, Lee SJ, Saisung S, Koecharoen K, Nguon C, Day NP, Socheat D, White NJ: Exploring the contribution of candidate genes to artemisinin resistance in Plasmodium falciparum. Antimicrob Agents Chemother 2010, 54:2886-2892.

42. Chen N, Chavchich M, Peters JM, Kyle DE, Gatton ML, Cheng Q: Deamplification of pfmdr1-Containing Amplicon on Chromosome 5 in Plasmodium falciparum is Associated with Reduced Resistance to 
Artelinic Acid In Vitro. Antimicrobial Agents and Chemotherapy 2010, 54:3395-3401.

43. Hunt P, Afonso A, Creasey A, Culleton R, Sidhu ABS, Logan J, Valderramos SG, McNae I, Cheesman S, Rosario Vd, Carter R, Fidock DA, Cravo P: Gene encoding a deubiquitinating enzyme is mutated in artesunate- and chloroquine-resistant rodent malaria parasites. Molecular Microbiology 2007, 65:27-40.

44. Hunt P, Martinelli A, Modrzynska K, Borges S, Creasey A, Rodrigues L, Beraldi D, Loewe L, Fawcett R, Kumar S, Thomson M, Trivedi U, Otto TD, Pain A, Blaxter M, Cravo P: Experimental evolution, genetic analysis and genome re-sequencing reveal the mutation conferring artemisinin resistance in an isogenic lineage of malaria parasites. BMC Genomics 2010, 11:499.

45. Klonis N, Crespo-Ortiz MP, Bottova I, Abu-Bakar N, Kenny S, Rosenthal PJ, Tilley L: Artemisinin activity against Plasmodium falciparum requires hemoglobin uptake and digestion. Proc Natl Acad Sci USA 2011, 108:11405-11410.

46. Flint J, Harding RM, Boyce AJ, Clegg JB: The population genetics of the haemoglobinopathies. Baillieres Clin Haematol 1998, 11:1-51.

47. Wiwanitkit V: Genetic disorders and malaria in Indo-China region. $J$ Vector Borne Dis 2008, 45:98-104.

48. Meshnick SR, Taylor TE, Kamchonwongpaisan S: Artemisinin and the antimalarial endoperoxides: from herbal remedy to targeted chemotherapy. Microbiol Rev 1996, 60:301-315.

49. Robert A, Bonduelle C, Laurent SAL, Meunier B: Heme alkylation by artemisinin and trioxaquines. J Phys Org Chem 2006, 19:562-569.

50. Yang YZ, Little B, Meshnick SR: Alkylation of proteins by artemisinin. Effects of heme, pH, and drug structure. Biochem Pharmacol 1994, 48:569-573.

51. Bhisutthibhan J, Meshnick SR: Immunoprecipitation of [(3)H] dihydroartemisinin translationally controlled tumor protein (TCTP) adducts from Plasmodium falciparum-infected erythrocytes by using anti-TCTP antibodies. Antimicrob Agents Chemother 2001, 45:2397-2399.

52. Bhisutthibhan J, Pan XQ, Hossler PA, Walker DJ, Yowell CA, Carlton J, Dame JB, Meshnick SR: The Plasmodium falciparum translationally controlled tumor protein homolog and its reaction with the antimalarial drug artemisinin. J Biol Chem 1998, 273:16192-16198.

53. Asawamahasakda W, Ittarat I, Pu YM, Ziffer H, Meshnick SR: Reaction of antimalarial endoperoxides with specific parasite proteins. Antimicrob Agents Chemother 1994, 38:1854-1858.

54. Hu G, Cabrera A, Kono M, Mok S, Chaal BK, Haase S, Engelberg K, Cheemadan S, Spielmann T, Preiser PR, Gilberger TW, Bozdech Z: Transcriptional profiling of growth perturbations of the human malaria parasite Plasmodium falciparum. Nat Biotechnol 2010, 28:91-98.

55. Campbell TL, De Silva EK, Olszewski KL, Elemento O, Llinas M: Identification and Genome-Wide Prediction of DNA Binding Specificities for the ApiAP2 Family of Regulators from the Malaria Parasite. PLoS Pathog 2010, 6:e1001165

56. Gonzales JM, Patel JJ, Ponmee N, Jiang L, Tan A, Maher SP, Wuchty S, Rathod PK, Ferdig MT, Templeton TJ: Regulatory Hotspots in the Malaria Parasite Genome Dictate Transcriptional Variation. PLoS Biology 2008, 6: e238.

57. Daily JP, Scanfeld D, Pochet N, Le Roch K, Plouffe D, Kamal M, Sarr O, Mboup S, Ndir O, Wypij D, Levasseur K, Thomas E, Tamayo P, Dong C, Zhou Y, Lander ES, Ndiaye D, Wirth D, Winzeler EA, Mesirov JP, Regev A: Distinct physiological states of Plasmodium falciparum in malariainfected patients. Nature 2007, 450:1091-1095.

58. Kim UJ, Han M, Kayne P, Grunstein M: Effects of histone $\mathrm{H} 4$ depletion on the cell cycle and transcription of Saccharomyces cerevisiae. EMBO J 1988, 7:2211-2219.

59. Prado F, Aguilera A: Partial Depletion of Histone H4 Increases Homologous Recombination-Mediated Genetic Instability. Molecular and Cellular Biology 2005, 25:1526-1536.

60. Mu J, Myers RA, Jiang H, Liu S, Ricklefs S, Waisberg M, Chotivanich K, Wilairatana P, Krudsood S, White NJ, Udomsangpetch R, Cui L, Ho M, Ou F, Li H, Song J, Li G, Wang X, Seila S, Sokunthea S, Socheat D, Sturdevant DE, Porcella SF, Fairhurst RM, Wellems TE, Awadalla P, Su XZ: Plasmodium falciparum genome-wide scans for positive selection, recombination hot spots and resistance to antimalarial drugs. Nat Genet 2010, 42:268-271.

61. Bozdech Z, Mok S, Hu G, Imwong M, Jaidee A, Russell B, Ginsburg H, Nosten F, Day NP, White NJ, Carlton JM, Preiser PR: The transcriptome of
Plasmodium vivax reveals divergence and diversity of transcriptional regulation in malaria parasites. Proc Natl Acad Sci USA 2008, 105:16290-16295.

62. Hu G, Llinas M, Li J, Preiser PR, Bozdech Z: Selection of long oligonucleotides for gene expression microarrays using weighted ranksum strategy. BMC Bioinformatics 2007, 8:350.

63. Kanehisa M, Goto S, Kawashima S, Okuno Y, Hattori M: The KEGG resource for deciphering the genome. Nucleic Acids Res 2004, 32:D277-280.

64. Ginsburg H: Malaria Parasite Metabolic Pathways.[http://sites.huji.ac.il/ malaria/].

65. Le Roch KG, Zhou Y, Blair PL, Grainger M, Moch JK, Haynes JD, De La Vega P, Holder AA, Batalov S, Carucci DJ, Winzeler EA: Discovery of gene function by expression profiling of the malaria parasite life cycle. Science 2003, 301:1503-1508.

66. Ashburner M, Ball CA, Blake JA, Botstein D, Butler H, Cherry JM, Davis AP, Dolinski K, Dwight SS, Eppig JT, Harris MA, Hill DP, Issel-Tarver L, Kasarskis A, Lewis S, Matese JC, Richardson JE, Ringwald M, Rubin GM, Sherlock G: Gene ontology: tool for the unification of biology. The Gene Ontology Consortium. Nat Genet 2000, 25:25-29.

67. Pique-Regi R, Ortega A, Asgharzadeh S: Joint estimation of copy number variation and reference intensities on multiple DNA arrays using GADA. Bioinformatics 2009, 25:1223-1230.

68. Snounou G: Genotyping of Plasmodium spp. Nested PCR. Methods Mol Med 2002, 72:103-116.

69. Crameri A, Marfurt J, Mugittu K, Maire N, Regos A, Coppee JY, Sismeiro O, Burki R, Huber E, Laubscher D, Puijalon O, Genton B, Felger I, Beck HP: Rapid microarray-based method for monitoring of all currently known single-nucleotide polymorphisms associated with parasite resistance to antimalaria drugs. J Clin Microbiol 2007, 45:3685-3691.

70. Ginsburg H: Progress in in silico functional genomics: the malaria Metabolic Pathways database. Trends Parasitol 2006, 22:238-240.

71. Edgar R, Domrachev M, Lash AE: Gene Expression Omnibus: NCBI gene expression and hybridization array data repository. Nucleic Acids Res 2002, 30:207-210.

doi:10.1186/1471-2164-12-391

Cite this article as: Mok et al: Artemisinin resistance in Plasmodium falciparum is associated with an altered temporal pattern of transcription. BMC Genomics 2011 12:391.

\section{Submit your next manuscript to BioMed Central and take full advantage of:}

- Convenient online submission

- Thorough peer review

- No space constraints or color figure charges

- Immediate publication on acceptance

- Inclusion in PubMed, CAS, Scopus and Google Scholar

- Research which is freely available for redistribution

Submit your manuscript at www.biomedcentral.com/submit
C Biomed Central 